\title{
PEMBUATAN APLIKASI PERIKLANAN SUSUNAN ACARA KEGIATAN UPACARA TRADISIONAL TABOT DI BENGKULU
}

\author{
Rizka Tri Alinse ${ }^{1}$, Arius Satoni Kurniawan ${ }^{2}$ \\ Program Studi Informatika Fakultas Ilmu Komputer Universitas Dehasen Bengkulu \\ Jalan Meranti Raya No.32 Kelurahan Sawah Lebar Kota Bengkulu Telp. 22027 Fax. (0736) 341139
}

\author{
Rizkatri07@gmail.com ${ }^{1}$, ariussatoni@unived.ac.id ${ }^{2}$
}

\begin{abstract}
Tabot culture has become a routine ritual of the city of Bengkulu. In addition, the Tabot event can also attract tourists to visit the city of Bengkulu. An ad can be said to be of quality if the ad is able to convey the contents of the advertisement to its customers. Because of the promotion needs, business actors make advertisements so that consumers are interested in using their products. Consumers can capture the contents of the ad if they want to follow and listen carefully, for that we as people in the world of multimedia must be able to make an ad that promotes the product or service with packaging that is attractive and easy to understand by consumers, so consumers are not bored first see the article before the ad is delivered. Then the quality of an advertisement is very influential on the quality of marketing of its products or services. If an advertisement is packaged as attractive as possible, the consumer can be interested and can easily respond to the message content of the ad. So that the producer can take the hearts of consumers and finally the product or service advertised will get a position in the hearts of consumers that will have an impact on the expected marketing results. On 1 to 10 Muharram $\mathrm{H}$ (Arabic Calendar) every year in the city of Bengkulu the Tabot Festival is held. The Tabot Festival is held based on the Tabot Cultural Party held by the people of Bengkulu City in commemoration of the death of Amir Hussain, the grandson of Prophet Muhammad SAW, in Padang Karbala (Iraq). This Tabot culture has become a routine ritual of the city of Bengkulu. In addition, the Tabot event can also attract tourists to visit the city of Bengkulu
\end{abstract}

Keywords - Expert System, Disease, Quail

\begin{abstract}
Abstrak - Budaya Tabot telah menjadi suatu ritual rutin masyarakat kota Bengkulu. Selain itu Acara tabot juga dapat menarik wisatawan untuk berkunjung ke kota Bengkulu. Sebuah iklan dapat dikatakan berkualitas jika iklan tersebut mampu menyampaikan isi dari iklan tersebut kepada para konsumennya. Karena kebutuhan promosi maka para pelaku dunia bisnis membuat iklan agar para konsumen tertarik menggunakan produknya. Para konsumen bisa menangkap isi iklan jika mereka mau mengikuti dan menyimak dengan seksama, untuk itu kita sebagai orang yang berkecimpung di dunia multimedia harus mampu membuat sebuah iklan yang mempromosikan yang menarik dan mudah dipahami konsumen, sehingga konsumen tidak bosan terlebih dahulu melihat ikaln tersebut sebelum iklan selesai disampaikan. Maka kualitas suatu iklan sangat berpengaruh terhadap kualitas pemasaran produk atau jasanya. Jika suatu iklan dikemas dengan semenarik mungkin maka konsumen itu dapat tertarik dan bisa merespon isi pesan dari iklan tersebut dengan mudah. Sehingga pihak produsen bisa mengambil hati para konsumen dan akhirnya produk atau jasa yang di iklankan akan mendapat posisi di hati para konsumen yang akan berdampak pada hasil pemasaran yang diharapkan. Budaya Tabot ini telah menjadi suatu ritual rutin masyarakat kota Bengkulu. Selain itu Acara tabot juga dapat menarik para pengunjung yang datang ke kota Bengkulu.
\end{abstract}

Kata Kunci - Tabot, Periklanan, Aplikasi

\section{PENDAHULUAN}

Perkembangan tekologi informasi yang semakin pesat, turut mempengaruhi persaingan di dunia bisnis. Dengan teknologi informasi yang semakin tinggi para pesaing di dunia bisnis akan sangat membutuhkan jasa untuk mempromosikan produk ataupun jasa agar mencapai keefektifan pemasaran, sehingga mereka mau mengeluarkan biaya untuk keperluan promosinya tersebut. Salah satu cara untuk mencapai kefektifan pemasaran tersebut adalah dengan media iklan.

Sebuah iklan dapat dikatakan berkualitas jika iklan tersebut mampu menyampaikan isi dari iklan tersebut kepada para konsumennya. Karena kebutuhan promosi maka para pelaku dunia bisnis membuat iklan agar para konsumen tertarik menggunakan produknya.
Para konsumen bisa menangkap isi iklan jika mereka mau mengikuti dan menyimak dengan seksama, untuk itu kita sebagai orang yang berkecimpung di dunia multimedia harus mampu membuat sebuah iklan yang mempromosikan produk atau jasa tersebut dengan kemasan yang menarik dan mudah dipahami konsumen, sehingga konsumen tidak bosan terlebih dahulu melihat ikaln tersebut sebelum iklan selesai disampaikan.

Maka kualitas suatu iklan sangat berpengaruh terhadap kualitas pemasaran produk atau jasanya. Jika suatu iklan dikemas dengan semenarik mungkin maka konsumen itu dapat tertarik dan bisa merespon isi pesan dari iklan tersebut dengan mudah. Sehingga pihak produsen bisa mengambil hati para konsumen dan mendapat posisi di hati para konsumen yang akan berdampak pada hasil pemasaran yang diharapkan. 
Untuk meningkatkan pengunjung atau wisatawan, diperlukan sebuah media periklanan yang yang menarik dan dapat menjelaskan berjalannya acara Tabot di Kota Bengkulu.

\section{LANDASAN TEORI}

\section{A. APLIKASI}

Menurut Kadir (2003:204), Aplikasi adalah suatu program yang dibuat oleh pemakai yang ditujukan untuk kepentingan khusus[1].

Aplikasi artinya penerapan, lamaran, penggunaan. Secara istilah aplikasi adalah: program siap pakai yang direka untuk melaksanakan suatu fungsi bagi pengguna atau aplikasi yang lain dan dapat digunakan oleh sasaran yang dituju.

\section{B. PERIKLANAN}

Menurut (www.kajianpustaka.com), periklanan adalah komunikasi non individu-individu, dengan jumlah biaya, melalui berbagai media non laba, serta individu-individu. Periklanan adalah usaha untuk memberikan suatau kesan melalui perimbangan dengan tujuan agar pembeli barang condong pada lembaga yan diberitahukan.

\section{TABOT}

Menurut (www.tabotbengkulu.com), Tabot atau Tabut adalah upacara tradisional masyarakat Bengkulu untuk mengenang tentang kisah kepahlawanan dan kematian cucu Nabi Muhammad SAW, Hasan dan Husein bin Ali bin Abi Thalib dalam peperangan dengan pasukan Ubaidillah bin Zaid di padang Karbala, Irak pada tanggal 10 Muharam 61 Hijriah $(681 \mathrm{M})$.

\section{METODE PENELITIAN}

Metode pengembangan sistem dengan tujuan meningkatkan dan mengefektifkan sistem yang sudah ada. Dengan langkah yang dilakukan dalam sistem baru ini yaitu dengan cara melakukan analisis kebutuhan data, mengumpulkan data, merancang dengan menggunakan pemodelan terstruktur, mengimplementasi rancangan ke dalam sebuah bentuk desain aplikasi periklanan yang interaktif.

\section{IV.HASIL DAN PEMBAHASAN}

\section{A. HASIL}

Ketika pertama kali aplikasi dijalankan maka menu awal akan tampil sebagai berikut:

1. Menu Pembuka
Menu pembuka berisi animasi logo pemerintah kota Bengkulu, judul Aplikasi Periklanan Susunan Acara Kegiatan Upacara Tradisional Tabot dan animasi gambar tentang kegiatan tabot. Pada bagian bawah terdapat informasi pembuat aplikasi dan sound control untuk mengatur volume lagu pengiring.

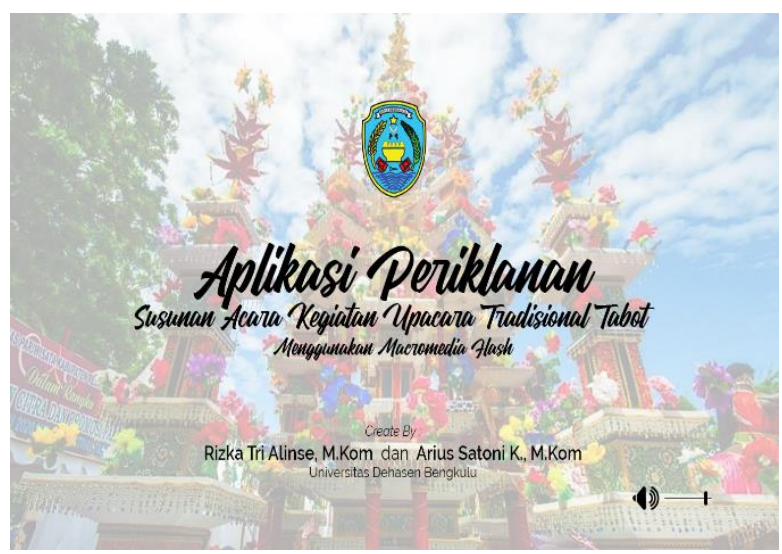

2. Menu Profil Kota Bengkulu

Menu profil kota Bengkulu menampilkan gambar tugu simpang 5 dan penjelasan mengenai profil kota Bengkulu. Karena penjelasan profil kota Bengkulu sangat panjang, maka diberikan tombol next untuk membaca profil selanjutnya dan tombol back untuk kembali ke bagian awal profil. Pada menu ini terdapat tombol "Sejarah Tabot" untuk melihat informasi tentang sejarah tabot.

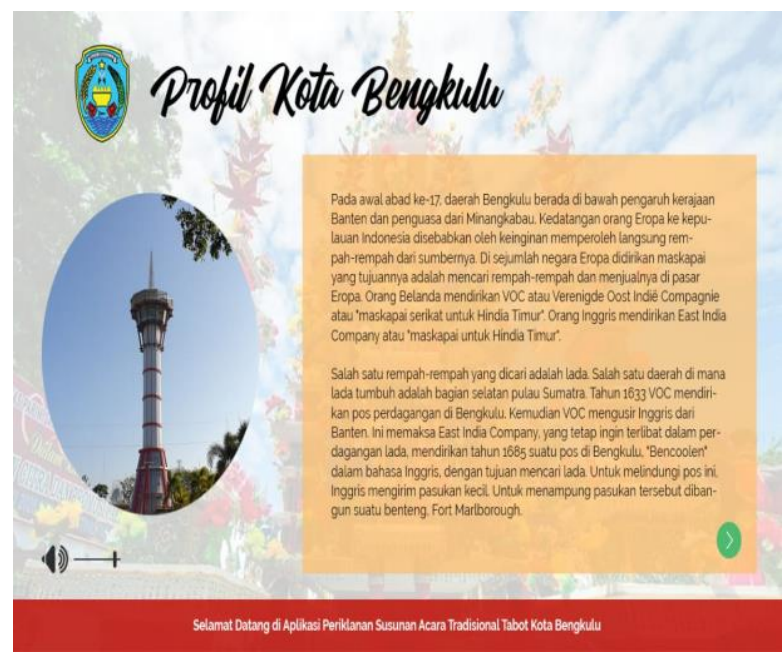

3. Menu Sejarah Tabot

Menu sejarah tabot menampilkan gambar tabot dan informasi tentang sejarah upacara tabot. Untuk membaca sejarah tabot yang panjang, pengguna dapat mengklik tombol next dan back. Pada menu ini terdapat tombol "Ritual Tabot" untuk menuju ke menu prosesi ritual tabot. 


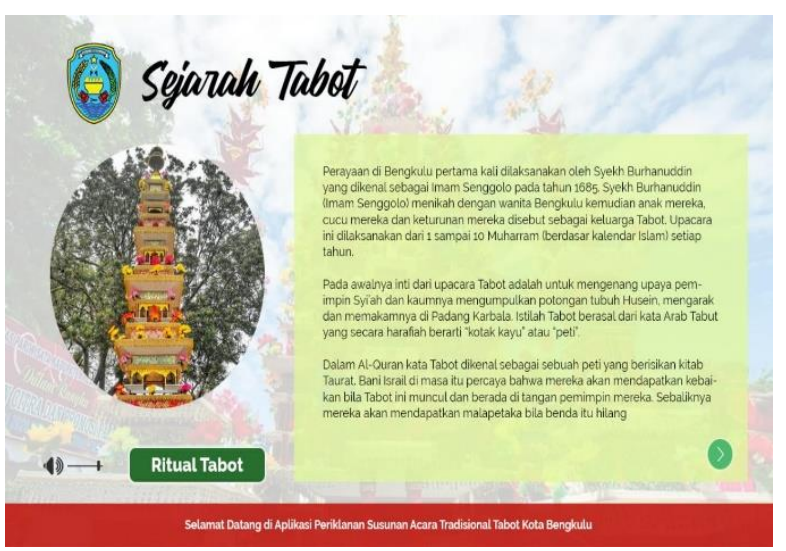

4. Menu Prosesi Ritual Tabot

Pada menu prosesi ritual tabot menampilkan video tentang riaual tabot dan penjelasan tentang hubungan tabot dan aspek ritual yang terkandung.Pengguna dapat mengklik pada masing-masing menu acara tabot yang disajikan. Selain itu juga terdapat tombol "Pesona Wisata" untuk menuju ke menu pesona wisata tabot dan tombol penutup untuk menuju ke menu penutup.

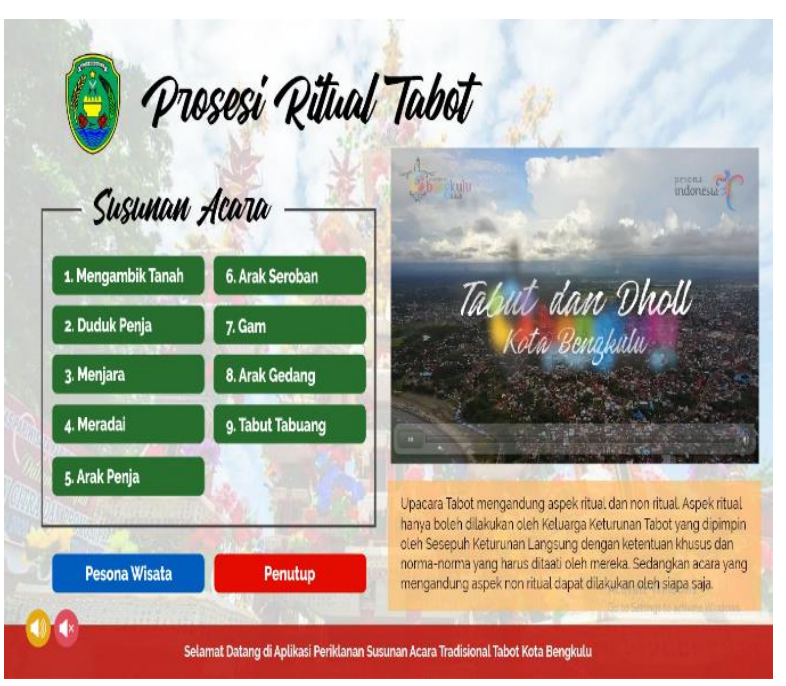

5. Menu Prosesi Ritual Mengambik Tanah

Menu prosesi ritual mengambik tanah menampilkan penjelasan tentang prosesi ritual mengambik tanak dilengkapi dengan video untuk mengetahui kegiatan ritual mengambik tanah tersebut. Pengguna dapat mengontrol video seperti play, stop dan pause. Terdapat tombol kembali untuk menuju ke menu sprosesi ritual tabot.

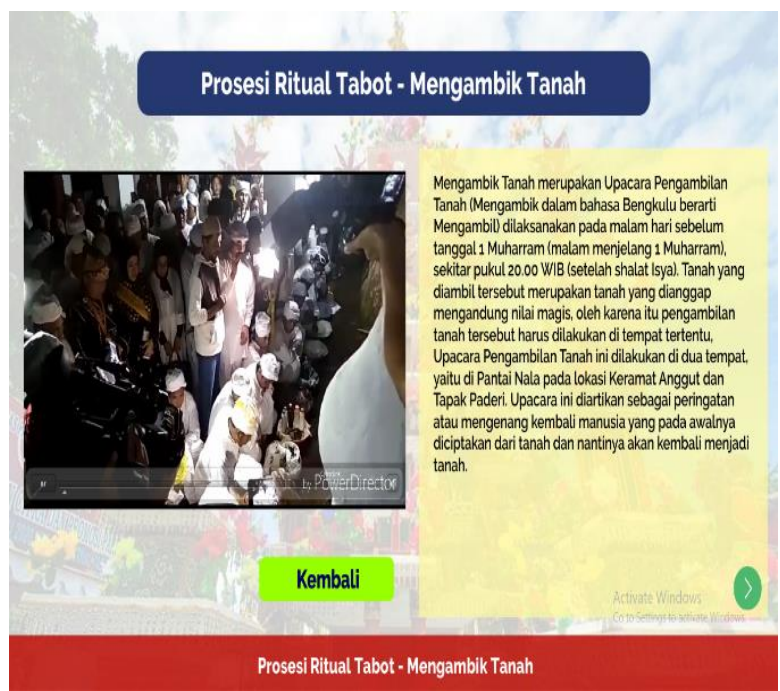

6. Menu Prosesi Ritual Duduk Penja

Menu prosesi ritual duduk penja menampilkan video tentang ritual duduk penja. Video ini dapat dikontrol seperti play, pause, dan stop. Pada menu ini juga ditampilkan penjelasan mengenai prosesi ritual duduk penja dalam bentuk teks.

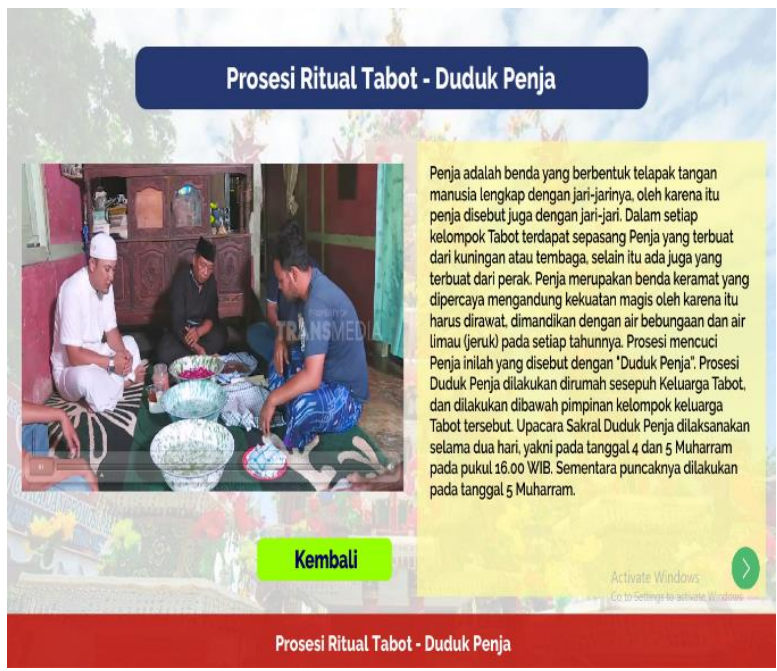

7. Menu Prosesi Ritual Menjara

Pada menu ini menampilkan video prosesi ritual menjara dan penjelasan tentang prosesi ritual menjara dalam bentuk teks. Selain itu terdapat tombol kembali untuk menuju menu prosesi ritual tabot. 


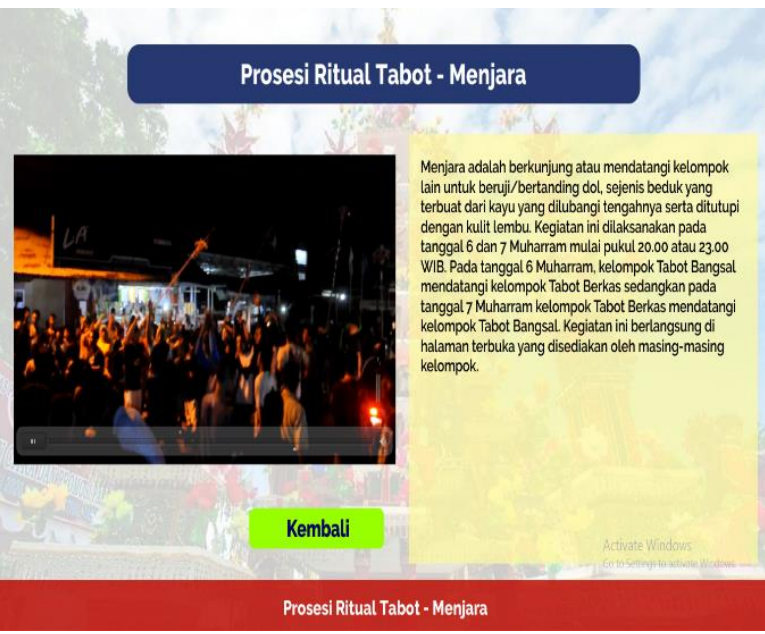

8. Menu Prosesi Ritual Meradai

Pada menu prosesi ritual meradai ditampilkan teks tentang penjelasan prosesi ritual meradai.

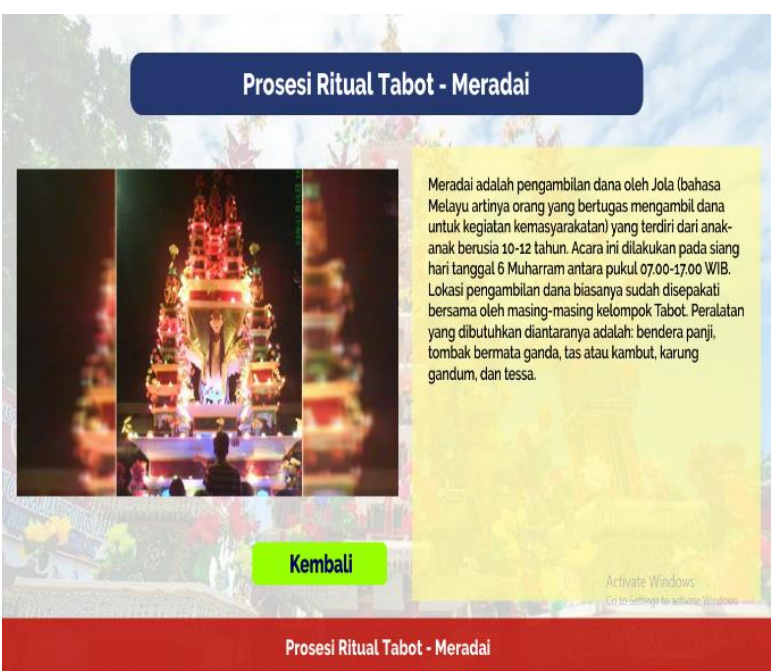

9. Menu Prosesi Ritual Arak Penja

Pada menu prosesi ritual arak penja ditampilkan video tentang prosesi tersebut.

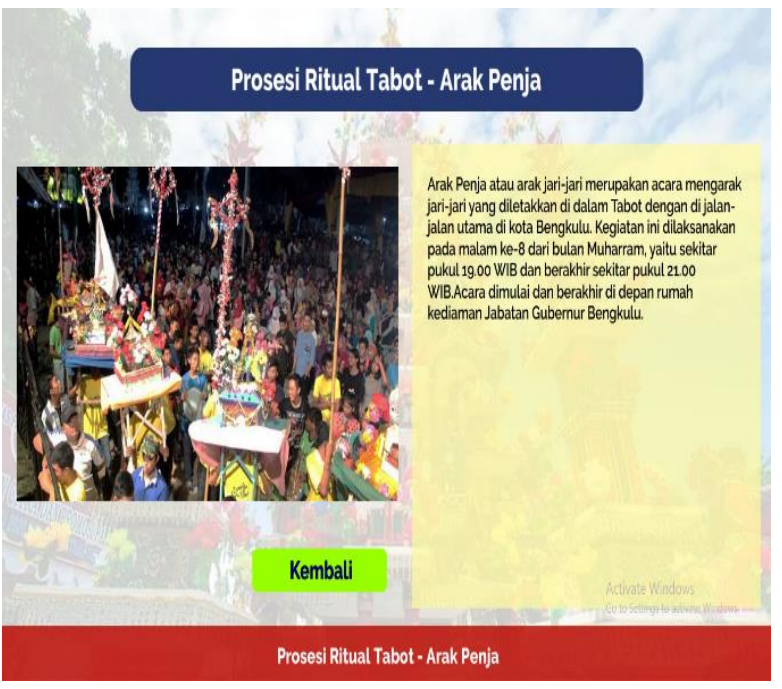

10. Menu Prosesi Ritual Arak Seroban

Menu prosesi ritual arak seroban menampilkan video tentang prosesi ritual arak seroban. Untuk kembali ke menu prosesi ritual tabot dapat di klik tombol kembali.

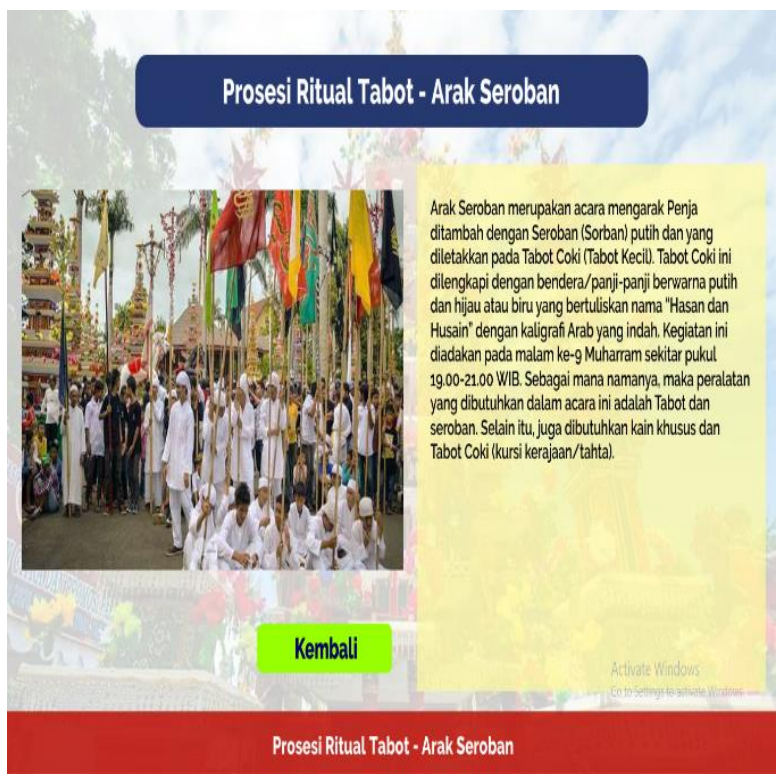

11. Menu Prosesi Ritual Gam

Pada menu prosesi ritual gam ditampilkan teks penjelasan tentang ritual gam pada acara upacara tabot. Terdapat animasi judul prosesi ritual gam dan pada bagian bawah terdapat animasi teks. Selain itu terdapat juga tombol kembali.

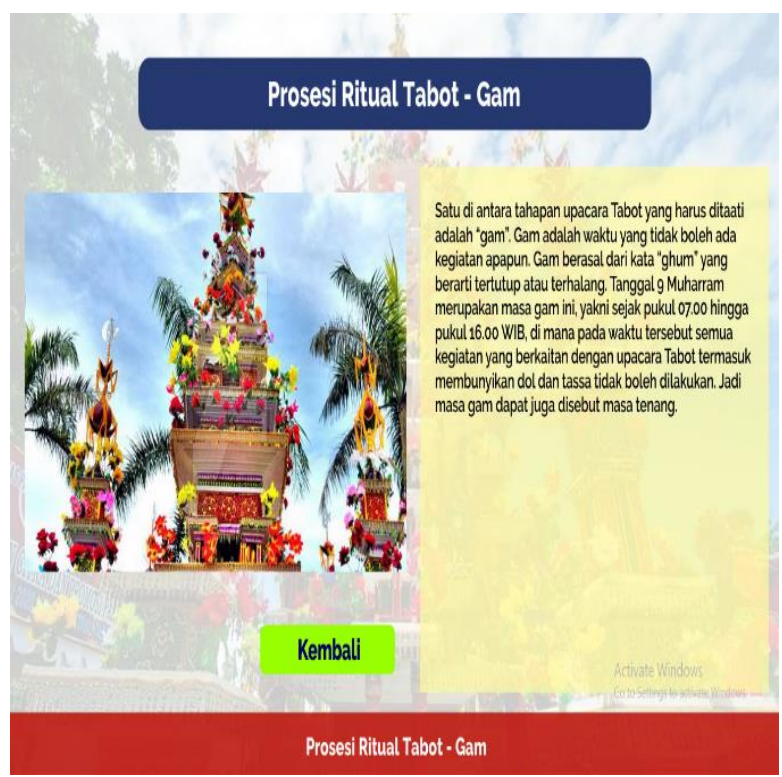

12. Menu Prosesi Ritual Arak Gedang

Menu prosesi ritual arak gedang menampilkan tentang ritual arak gedang dan tabut besanding yang merupakan awal dari ritual arak gedang. Selain itu juga terdapat penjelasan teks tentang ritual arak gedang. dan 
tombol kembali untuk kembali ke menu prosesi ritual tabot.

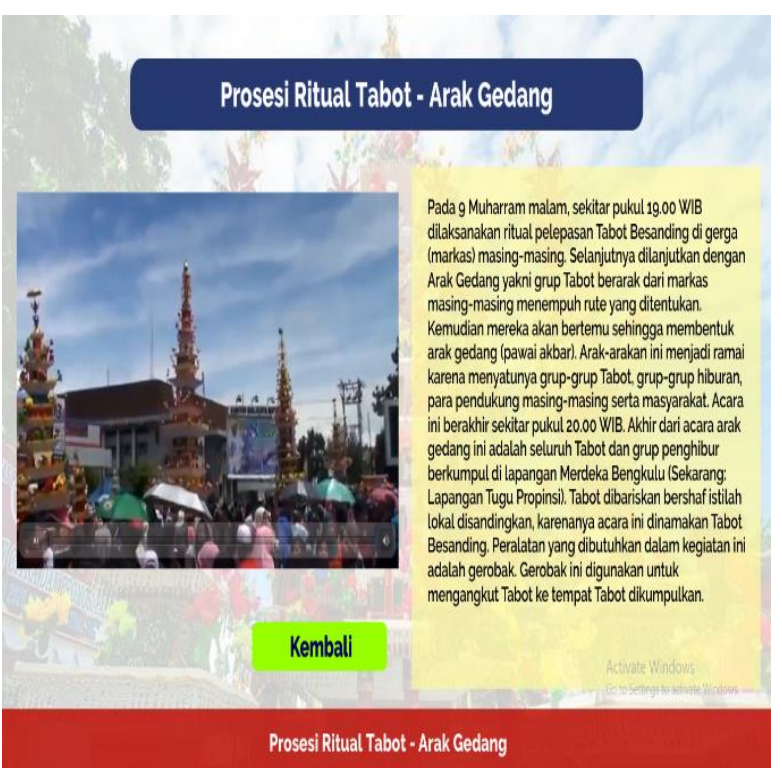

13. Menu Prosesi Ritual Tabut Tebuang

Pada menu prosesi ritual tabut tebuang menampilkan video prosesi ritual tersebut. Selain itu juga penjelasan dalam bentuk teks dan tombol kembali untuk kembali ke menu susunan acara ritual tabot.

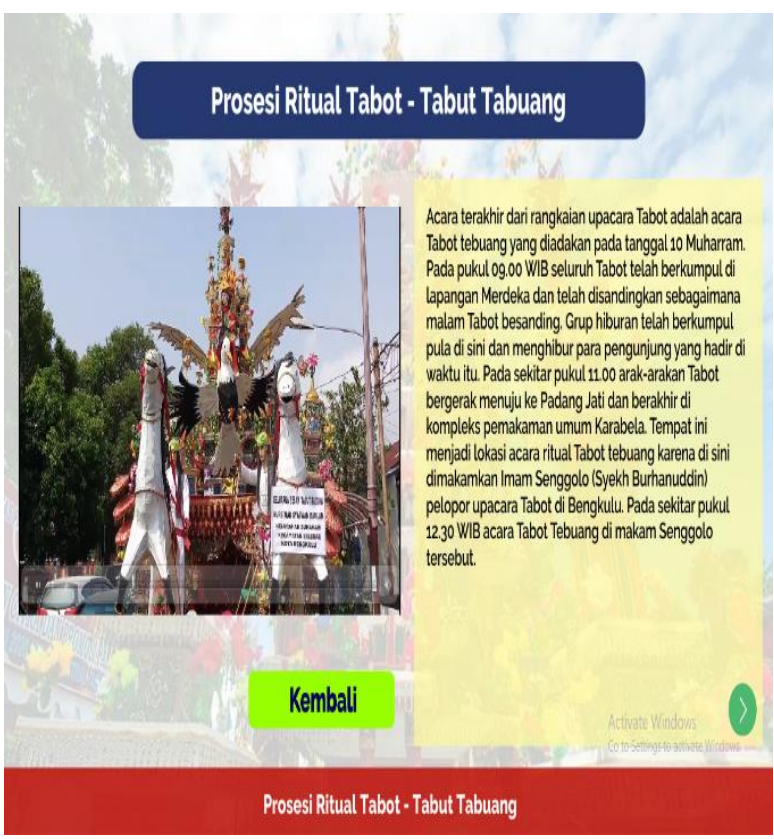

14. Menu Pesona Wisata Acara Tabot

Menu ini menampilkan penjelasan tentang pesona wisata atau unsur-unsur wisata pada acara tabot. Penjelasan ditampilkan dalam bentuk teks. Selain itu terdapat juga tombol kembali untuk menuju ke menu sebelumnya yaitu menu prosesi ritual tabot.

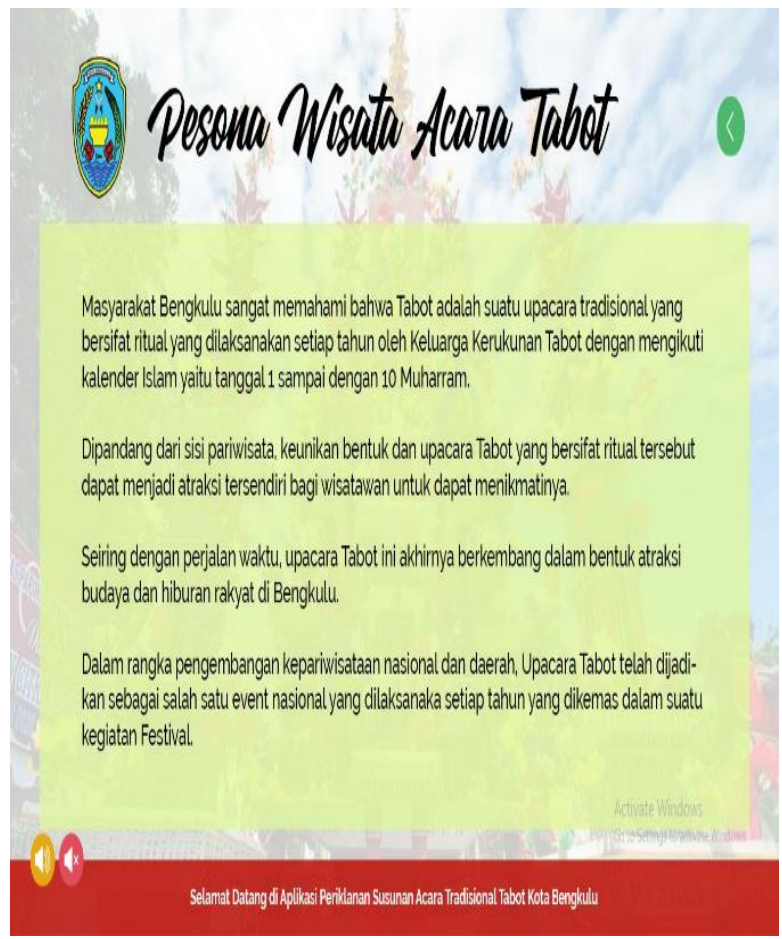

\section{Menu Penutup}

Menu penutup adalah menu terakhir yang muncuk ketika di klik tombol penutup. Pada menu penutup terdapat ucapan terima kasih. Selain itu terdapat tombol keluar untuk menutup aplikasi.

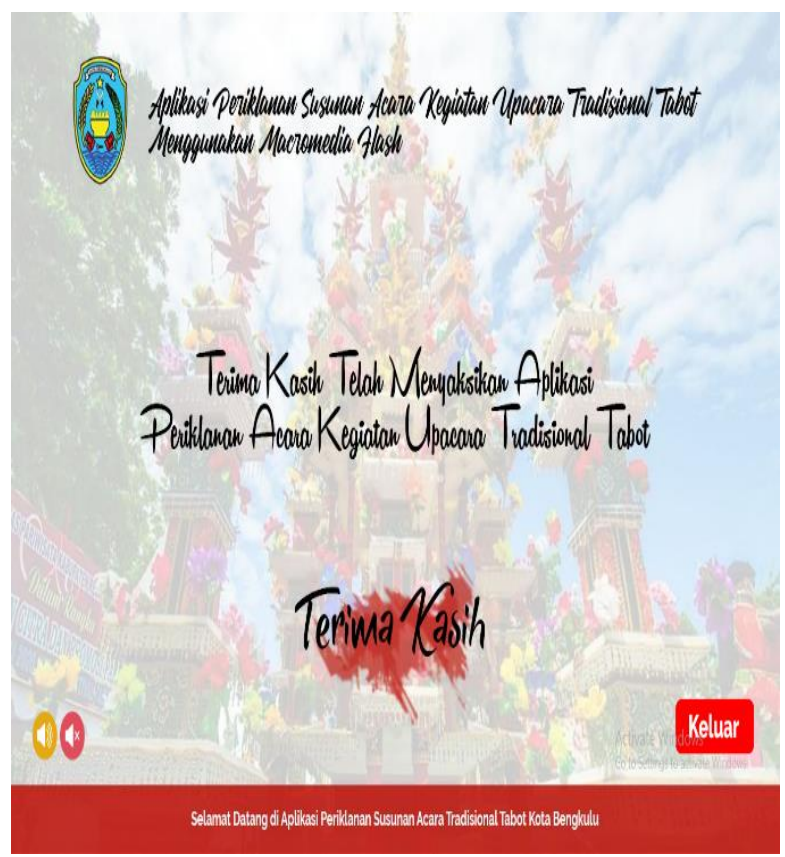




\section{V.PENUTUP}

Aplikasi periklanan susunan acara kegiatan upacara tradisional tabot dibutuhkan pada Dinas Pariwisata sebagai usaha untuk meningkatkan pengunjung dan wisatawan. Dengan teknologi komputer dan multimedia kebutuhan itu dapat terpenuhi. Macromedia flash 8 dapat digunakan untuk mebuat aplikasi periklanan yang dilengkapi dengan teks, gambar, animasi dan video sehingga dengan aplikasi periklanan yang dihasilkan akan menjadi lebih menarik.

\section{DAFTAR PUSTAKA}

[1] Kadir, Abdul, 2003, Pengantar Sistem Informasi, C.V Andi Offset, Yogyakarta

[2] Anonimous, 2014, Tabot Bengkulu, url : http://tabotbengkulu.com.

[3] Muchlisin, 2014, Teori Periklanan, url: http://www.kajianpustaka.com/2012/11/teoriperiklanan.html 